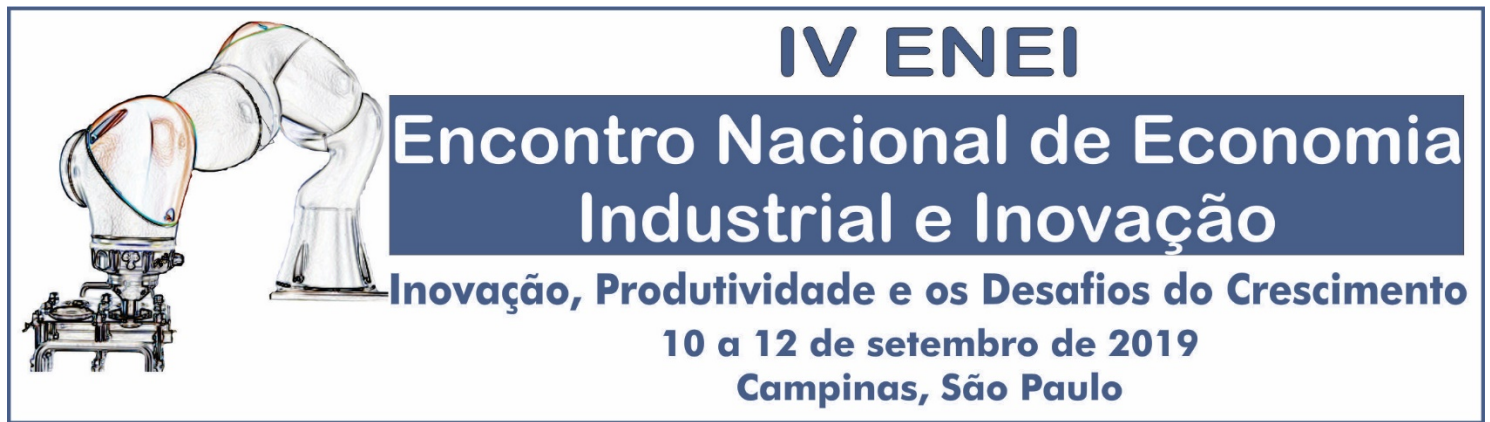

\title{
Política de Inovação na Era do Capitalismo de Plataformas
}

Victo José da Silva Neto (Universidade Estadual de Campinas), Maria Beatriz Machado Bonacelli (Universidade Estadual de Campinas), Carlos Américo Pacheco (Universidade Estadual de Campinas) 


\section{Política de Inovação na Era do Capitalismo de Plataformas}

Victo José da Silva Neto (Universidade Estadual de Campinas), Maria Beatriz Machado Bonacelli (Universidade Estadual de Campinas), Carlos Américo Pacheco (Universidade Estadual de Campinas)

\section{Área ABEIN 6.2 - Politicas de Ciência, Tecnologia e Inovação}

\section{JEL Classification: $\mathrm{O} 38$}

Resumo: a economia digital deixou de ser setorialmente localizada. Pervasiva ao tecido econômico, sua lógica se impõe via processos de digitalização de serviços/produtos e difusão das plataformas como modelo organizacional. As alterações são substanciais em termos de lógica competitiva, mecanismos de inovação e atualização normativa. As plataformas trazem oportunidades e desafios para as economias nacionais. Em vista disso, organizações internacionais enfatizam a necessidade de atualizar políticas nacionais de inovação e diversos países tem estabelecido estratégias digitais. Neste artigo debatemos as principais características da economia digital e buscamos sua gênese na 'nova economia' dos anos 1990. Em seguida, apresentamos os principais pontos que fazem das plataformas digitais a best-practice organizacional da economia digital. Finalmente, discutimos aspectos da E-Digital, a estratégia de transformação digital desenvolvida pelo governo brasileiro: sua articulação com uma agenda política mais abrangente; definição de agência; visão de paradigma de inovação e compreensão do potencial e difusão da plataformização.

Abstract: the digital economy is no longer confined to specific sectors. Pervasive to the economic fabric, its logic imposes through processes of services/product digitization and the diffusion of platforms as organizational model. Changes are substantial in terms of competitive logic, innovation mechanisms and normative updating. Platforms bring opportunities and challenges for national economies. In view of this, international organizations emphasize the need to update national innovation policies and several countries have established digital strategies. Here we discuss the main features of the digital economy and search for its genesis in the 'new economy' of the 1990s. Next, we present the main points that make digital platforms the organizational best practice of the digital economy. Finally, we discuss aspects of EDigital, the digital transformation strategy developed by the Brazilian government: its articulation with a broader political agenda; definition of agency; innovation paradigm definition and understanding of the potential and diffusion of platformization.

Palavras chave: plataformas; plataformas digitais; plataformização; inovação digital; economia digital; política de inovação

Keywords: platforms; digital platforms; platformization; digital innovation; digital economy; innovation policy

\section{Introdução}

O estado brasileiro reconhece, na mais recente versão da Estratégia Nacional de Ciência, Tecnologia e Inovação, o avanço da digitalização ${ }^{1}$ em diversas áreas da economia e da sociedade (MCTIC, 2016). Por este motivo, "Economia e Sociedade Digital” são um dos doze temas estratégicos daquele documento (MCTIC, 2016, p.103). Talvez mais importante do que a lista temática relevante para uma estratégia digital (IoT, Big Data, etc.), tenha sido afirmar que uma das tendências mundiais em políticas de CTI:

\footnotetext{
1 Para uma abordagem ampla sobre a fase histórica da economia marcada por este processo ver Brynjolfsson e McAffe, 2014, 2017. Para os efeitos microeconômicos da economia digital, em especial custos de transação, ver Goldfarb e Tucker, 2017. Os efeitos sobre os fluxos de conhecimentos são tratados em Fabre, 2016. Por fim, aspectos sociais e políticos da digitalização e da plataformização da economia estão em Moore, 2016; Kenney e Zysman, 2016; Zysman e Kenney, 2018.
} 
“[...] é a adoção da inovação aberta ou open innovation, um modelo de inovação altamente colaborativo, promovido pelos chamados "intermediários de inovação". Esses entes são responsáveis por atividades que envolvem desde o preenchimento de lacunas de informação até a criação de espaços que favoreçam as interações entre indivíduos e organizações, identificando potenciais colaboradores" (MCTIC, 2016, p. 54, grifo nosso).

De forma não intencional, o documento ressalta a importância das plataformas para a inovação. Estes "entes" indefinidos - "intermediários de inovação" que criam espaços facilitadores de interação entre diversos agentes - foram descritos por um corpo recente de literatura como plataformas (GAWER; CUSUMANO, 2002; GAWER, 2009; GAWER, 2014; SRNICEK, 2017; KENNEY; ZYSMAN, 2016; ZYSMAN; KENNEY, 2018; PARKER et al., 2016). As plataformas, entretanto, muito além de simples intermediários de inovação, constituem um novo modelo organizacional e de negócios (PARKER et al., 2016, p. ix).

Em uma formulação inicial, plataformas são "negócios baseados na promoção de interações geradoras-de-valor entre produtores externos e consumidores" (PARKER et al., 2016, p. 5, tradução livre). Elas criam espaços que viabilizam e fomentam interações entre indivíduos, organizações e, especificamente no universo que nos interessa, agentes econômicos. Cartões de crédito são plataformas que permitem a interação entre compradores e vendedores; sistemas operacionais abertos, como o Google Android, são plataformas que unem usuários e desenvolvedores de aplicativos; a Cataki é uma plataforma que conecta catadores de material reciclável com empresas que adquirem este tipo de insumo. São muito diversas as formas concretas em que este modelo organizacional se manifesta, embora possam ser identificados elementos comuns a toda plataforma (BALDWIN; WOODARD, 2009; GAWER, 2009; GAWER, 2014). Sua relação com a inovação tampouco é simples e unívoca: depende de diversos fatores, como a arquitetura da plataforma, o engajamento de complementadores, o grau de abertura e a governança para apropriação do valor. Em vista disso, a relação das plataformas com o paradigma da inovação aberta (CHESBROUGH, 2003), ainda é um tema em aberto. Autores como Yoo et al. (2012) propõem uma nova dinâmica para os processos de inovação mediados pelas plataformas digitais.

As plataformas digitais são definidas como "frameworks digitais multilaterais que intermediam e dão forma às regras que os participantes obedecem ao interagir entre si” (KENNEY; ZYSMAN, 2018, p. 56, tradução livre). Ao definirem regras, as plataformas tornam-se "estruturas reguladoras, e, portanto, sistemas de governança” (KENNEY; ZYSMAN, 2018, p. 54, tradução livre). Capazes de definir as regras de interação em seu meio, as plataformas são capazes de arbitrar sobre os incentivos para inovar, embora sempre haja um grau de indeterminação ex-ante no comportamento do seu ecossistema circundante (BOUDREAU, 2010; BOUDREAU 2012; PARKER et al., 2016). Não obstante sua relação não-unívoca com a inovação, a importância das plataformas na economia digital é consensual, ensejando formulações sobre a economia digital não como um setor ampliado baseado nas tecnologias de informação e comunicação (TICs), mas como uma fase do capitalismo (SRNICEK, 2017; BRYNJOLFSSON; McAFFE, 2014; BRYNJOLFSSON; McAFFE, 2017; KENNEY; ZYSMAN, 2016). Para Kenney et al. (2019, p. 2), a plataformização - o processo de difusão da plataforma enquanto best-practice organizacional - tem reflexos sobre quase todas as indústrias, sobre o mundo do trabalho e sobre o padrão de competição. Ou seja, as plataformas operam alterações substantivas no core do capitalismo. Parker et al. (2016, p. 159) afirmam que "plataformas privadas nesta escala [Facebook, Google, Alibaba] controlam sistemas econômicos maiores do que quase todas as economias nacionais, a não ser as maiores" e ainda que "gostemos ou não, firmas como esta [plataformas] já atuam como reguladores nãooficiais e não-eleitos de milhões de vidas” (PARKER et al., 2016, p. 159-160).

Organizações internacionais corroboram esta percepção. A economia global se tornou uma economia digital, de acordo com CEPAL (2016. p. 91), uma vez que a competitividade e o crescimento se dão em função da convergência entre tecnologias digitais, plataformas e outros mecanismos baseados na Internet. Ao mesmo tempo, a CEPAL preocupa-se com o fato de que a digitalização é impulsionada por tecnologias forâneas em sua grande maioria (CEPAL, 2016, p. 56) e com o domínio das plataformas 
digitais estrangeiras no mercado latino-americano (CEPAL, 2016, p. 63). O FMI (2018) optou por seguir uma abordagem estatística, criando novas formas de mensuração da economia digital. UNCTAD (2017) aborda a digitalização de processos e a utilização de plataformas na agricultura, no turismo e a importância crescente de plataformas globais. As plataformas globais permitiriam o acesso de pequenas e médias empresas a mercados antes inacessíveis (UNCTAD, 2017, p. 55). O rebaixamento dos custos de instalação (set-up costs) propiciado pelas plataformas incentiva o empreendedorismo e é ressaltado pela OCDE (2018). O efeito da plataformização sobre as pequenas e médias empresas não se dá somente via rebaixamento de custos e ampliação de mercados. De Marco et al. (2019), em relatório técnico do Joint Research Center (JRC) da União Europeia, encontram evidências claras de inovação via plataformas digitais em um subconjunto de 2.320 pequenas e médias empresas europeias (de um universo amostral de 33.056 empresas com propostas submetidas ao SMEi). Em suma, "With such broad and deep transformations in innovation under way, it is important to evaluate whether policy support to innovation should adapt, and in what directions" (OECD, 2018, p. 5).

Seguindo a multiplicação de Agendas Digitais Nacionais (CEPAL, 2016), o Brasil publicou, via MCTIC, a Estratégia Brasileira para a Transformação Digital (E-Digital) (MCTIC, 2018). Este documento conjuga uma série de diagnósticos com relação ao estado atual da digitalização no país e os conjuga com visões de mundo para delinear uma estratégia de longo prazo, de forma a coordenar as diferentes ações relacionadas ao tema em função de uma visão coerente e unificada "de modo a apoiar a digitalização dos processos produtivos e a capacitação para o ambiente digital, promovendo a geração de valor e o crescimento econômico" (MCTIC, 2018, p. 8). Como veremos com detalhes, o documento dedica um amplo espaço à discussão das plataformas digitais como novo modelo de negócios. No entanto, um diagnóstico superficial com respeito as características, a diversidade de plataformas, seus potenciais retornos e a importância da regulação geram diretrizes normativas incompletas e/ou inconclusivas sobre quais as políticas de inovação adequadas tendo em vista a complexidade e potencialidade deste novo arranjo organizacional. O documento não cita pesquisas empíricas que tenham se dedicado ao estudo da difusão da plataformização no Brasil.

É na esteira do surgimento deste novo paradigma organizacional que ressoamos o alerta da OCDE (2018, p. 5) quanto a adaptação das políticas de inovação a este novo contexto e daí derivamos a pergunta de pesquisa: Como a política de inovação no Brasil deve se adaptar à era da plataformização? Em outros termos, o que a plataformização implica para a política de inovação? Esperamos, com o presente artigo, fornecer subsídios iniciais para colaborar na construção desta agenda. Para começar a responder as questões levantadas, nos baseamos em uma extensa revisão de literatura com respeito à economia digital e às plataformas digitais. Em seguida, realizamos a análise documental da principal publicação nacional com respeito à política de inovação digital, a Estratégia Brasileira para a Transformação Digital (EDigital) (MCTIC, 2018). Esta metodologia nos permite avaliar o que o estado brasileiro abordou e o que deixou de fora, no que diz respeito ao cânone da literatura em formação, em sua estratégia de digitalização da economia. No que diz respeito à forma, segue-se a esta introdução a segunda seção, na qual abordamos as diferenças gerais entre a "nova economia" dos anos 1990/2000 e a economia digital atual. Definimos a economia digital em torno de uma tendência processual/tecnológica (digitalização), e uma tendência organizacional/tecnológica (plataformização). $\mathrm{Na}$ terceira seção apresentamos as principais características deste modelo organizacional epitomizado pela plataforma digital. $\mathrm{Na}$ quarta seção analisamos a E-Digital e tecemos algumas considerações tendo em vista o exposto nas sessões anteriores. Finalmente, a quinta e última seção traz uma breve discussão e elenca os próximos passos nesta agenda de pesquisa em construção.

\section{Da 'nova economia' a 'economia digital'}

Usualmente, quando há um conjunto complexo de fenômenos sociais novos, pesquisadores os agrupam sob o rótulo de uma nova era ou época. Eventualmente, a entrada nestes novos períodos se dá via 'revolução' - o que basicamente indica alterações rápidas no status quo econômico, político e/ou social. Embora colateralmente fiquemos com a vulgarização do termo 'revolução', é uma maneira convencional de se remeter a estes pontos na história em que um novo arranjo social se impõe. A 
revolução digital corresponde a este arquétipo de construto conceitual histórico: mudanças rápidas e concomitantes, cujo denominador comum são as tecnologias digitais, afetando múltiplas dimensões da sociedade: da guerra cibernética (cyber-warfare) aos desafios às democracias ${ }^{2}$. Embora seja possível tratar da revolução digital de diversas perspectivas, o que é preciso identificar para o propósito deste artigo é o desdobramento econômico e técnico-científico deste fenômeno mais amplo. Uma forma útil de começar a entender a economia digital é comparar suas características definidoras com o que veio imediatamente antes dela.

\section{Gênese da Economia Digital: evolução > revolução}

Manuel Castells, em sua principal obra, apresenta o que veio a ser a semente da revolução digital: a difusão das tecnologias de informação e comunicação e seus amplos impactos sociais. $\mathrm{O}$ autor inicia o primeiro de seus três volumes discorrendo sobre a "nova economia" - obtendo subsídios para posteriormente discutir aspectos sociais e culturais (CASTELLS, 2017, vol. II). Da própria terminologia empregada naquele momento - "nova economia" - deduz-se o caráter imaturo/inconcluso do fenômeno analisado: pesquisadores percebiam algo novo, porém ainda não conseguiam especificá-lo. É elucidativo que Castells, em passagem decisiva, afirme que a 'especificidade histórica' da nova economia é 'expandir o potencial da economia industrial madura', ou que 'a nova economia não se opõe à economia industrial, mas a contém' (CASTELLS, 2017, p. 154). Parker et al. (2016) confirmam a existência de duas fases (em termos de modelos organizacionais) de disrupção econômica causadas pela exploração comercial da Internet $^{3}$. A primeira fase (que entendemos como o período da 'nova economia'), foi definida pelos autores como a fase em que "pipelines ${ }^{4}$ eficientes devoram pipelines ineficientes". A eficiência provinha da capacidade logística e de distribuição permitida pela conectividade, as vezes com custo marginal de distribuição próximo de zero, vantagens rapidamente absorvidas pelos setores de mídia e atacadista (PARKER et al., 2016, p. 63). No entanto, a tecnologia estava sendo introjetada em um modelo organizacional projetado para outra época. Castells desenvolveu sua interpretação da 'nova economia' em um momento de transição. Daí que sua análise seja baseada parcialmente em fatos que ocorreram até meados da década de 1990 e parcialmente em extrapolações baseadas em revoluções tecnológicas passadas. A "nova economia", ao fim e ao cabo, foi interpretada como a economia industrial com uma esfera de circulação ampliada (mercados globais) e setorialmente informatizada (CASTELLS, 2017, p. 155). A força do paradigma tecnológico é relativizada no momento analisado por Castells, que reconhece que foram forças políticas que colocaram em marcha a globalização econômica via homogeneização institucional dos mercados (OMC, FMI, Banco Mundial sendo seus vetores), utilizando-se das TICs como ferramenta para viabilizar o aumento da lucratividade das empresas ocidentais. Naquele momento (meados da década de 1990), era cedo para divisar a difusão do paradigma - e Castells anteviu mais do que a maioria o que estava por vir.

E o que veio? Embora tenha citado Carlota Perez apenas uma única vez em sua obra, Castells mobiliza a noção de paradigmas tecno-econômicos (PEREZ, 1983) ao longo de todo o seu primeiro volume. Em especial, ele recorre à complementaridade (e assincronicidade) entre mudanças tecnológicas e mudanças organizacionais. Sem estas últimas, o potencial da revolução tecnológica é constrangido ${ }^{5}$ (CASTELLS, 2017, p. 235; PEREZ, 2002, p. 15; PARKER et al., 2016, p. 66-67). Quase um quarto de século depois de $A$ Sociedade em Rede, podemos observar a mudança organizacional anunciada. Chega o momento das plataformas, o segundo pilar da economia digital. O primeiro pilar, a digitalização

\footnotetext{
${ }^{2}$ Moore (2016) enfatiza a dominância digital das "tech giants" (as grandes empresas de tecnologia digital) e a ameaça que elas trazem, com seu poder monopolístico, ao exercício das democracias, do direito de livre associação, comunicação e do papel cívico individual.

3 "The story of Internet-enabled disruption as we've witnessed it so far has ocurred in two main stages" (PARKER et al., 2016, p. 63).

${ }_{4}$ "“...] a pipeline is a business that employs a step-by-step arrangement for creating and transferring value, with producers at one end and consumers at the other" (PARKER et al., 2016, p. 6).

5 "[...] the old organizational models cannot cope with or take full advantage of the new potential [of the technological revolution]. The new possibilities and their requirements also unleash a profound transformation in 'the way of doing things' across the whole economy and beyond" (PEREZ, 2002, p. 15).
} 
(digitisation ou digitization), co-evolue com a formação deste novo paradigma organizacional. A economia digital inaugura a segunda fase de disrupção promovida pela conectividade. Nos termos de Parker et al. (2016), na segunda fase, "plataformas devoram pipelines".

Embora as plataformas sejam tema da próxima sessão, temos de adiantar aqui algumas definições: "At the most general level, platforms are digital infrastructures that enable two or more groups to interact. They therefore position themselves as intermediaries that bring together different users: customers, advertisers, service providers, producers, suppliers and even physical objects" (SRNICEK, 2017, p. 43). A definição apresentada é um bom ponto de partida. Ela contém os elementos técnicos ("digital infrastructures"), a importância em termos econômicos do posicionamento para as plataformas ("intermediaries") e a atividade fomentada por elas entre agentes econômicos a partir da qual geram valor ("groups to interact"). Existem diversos tipos de plataformas. A Amazon Web Service (AWS), por exemplo, fornece capacidade computacional na nuvem para outros negócios e outras plataformas. A GE e a Siemens atualmente lideram consórcios nacionais em seus respectivos países para se tornarem as líderes em plataformas industriais - que fornecerão sensoriamento e processamento de informações a todas as outras indústrias 'digitalizadas'. Há também as mais populares plataformas on-demand: Netflix, Spotify, Uber, AirBnb. O que há de comum entre elas é o fato de terem sido selecionadas pelo ambiente econômico como o modelo dominante de empresa no século XXI (EVANS; SCHMALENSEE, 2016) e impulsionadas para todos os mercados e indústrias pelo capital financeiro ansioso por se posicionar como financiador do modelo vencedor (SRNICEK, 2017; PEREZ, 2002). A questão que deve ser encarada nesta passagem de fase é porque a plataformização emergiu como modelo "vencedor", ao invés de outra configuração organizacional?

Em algumas passagens, Castells faz referência ao contexto caótico e incerto no qual as empresas estão mergulhadas na passagem do século XX para o XXI (CASTELLS, 2017, p. 255-256.). Sua conceituação da empresa em rede como unidade fundamental seria a resposta para este desafio: agindo coletivamente, custos e riscos seriam diluídos e tornados suportáveis (CASTELLS, 2017, p. 256). No entanto, não chegamos a nenhuma empresa em rede - fenômeno muito distinto de redes de empresas. A importância das redes é indiscutível. Elas são, para usar uma formulação do próprio autor, o "espaço dos fluxos": fluxos de capitais, tecnologias, etc., No entanto, esta alteração na configuração dos fluxos não foi acompanhada de alterações substantivas na configuração dos direitos de propriedade ${ }^{6}$. A propriedade continua sendo nucleada na empresa, salvo contratuação ad hoc entre as partes participantes de um empreendimento. Mesmo bens comuns do conhecimento, que tem a característica intrínseca de serem não-rivais, tem direitos de propriedade intelectual erigidos em seu entorno para permitir a apropriação privada $^{7}$. De fato, este descompasso entre a contribuição para a geração de valor dada por diversos agentes e apropriação de valor por alguns privilegiados/bem posicionados (empresas em posições-chave, e.g.: plataformas) é um dos problemas fundamentais do capitalismo moderno ${ }^{8}$.

Voltando ao ponto, o que explica o sucesso das plataformas? Castells estava correto quanto ao ambiente no qual as empresas operavam na virada do século: hiperconectado, incerto e, em algum nível, caótico. Investidores, em sua perpétua busca por acumulação, dão preferência natural - coeteris paribus a empreendimentos menos incertos e menos arriscados. Navegar na nova morfologia dos mercados criada a partir da internet era a passagem para um terreno muito incerto. Ao mesmo tempo em que o potencial de lucros era grande, os riscos eram enormes: em que redes a empresa deveria se engajar? O que garantia que uma informação era relevante? Como a empresa deveria se posicionar sobre uma nova informação? Os concorrentes tinham o mesmo acesso a informação? Em suma, quem fazia a curadoria das informações relevantes nesta enxurrada de dados e conexões? Carlsson (2004:261) anteviu qual seria o

\footnotetext{
${ }^{6}$ Carlsson inclusive chega a mencionar que a capacidade de navegar neste mundo de informações e prover a intermediação entre agentes econômicos é um "conhecimento proprietário e especializado; é a competência central do negócio" (CARLSSON, 2004, p. 261).

${ }^{7}$ Para uma ampla discussão sobre este tema ver Y. Benkler (2006)

${ }^{8}$ Para uma discussão aprofundada sobre a participação do Estado na geração de valor via inovação ver Mazucato (2014; 2017).

Para uma discussão sobre a participação do Estado, das empresas e dos trabalhadores no processo de inovação (sem a devida distribuição equânime do valor gerado) ver Lazonick;Mazzucato (2013).
} 
tipo de serviços que emergiria desta nova configuração do espaço onde se dava a competição econômica, marcada pela superabundância de informações e conexões: serviços de publicidade focalizada; conectar start-ups a novas fontes de financiamento; portais de emprego que mediassem a conexão entre empregadores e empregados - na linguagem atual, plataformas:

\begin{abstract}
"As it turns out, they all [digital economy new services] involve some type of brokerage function that requires real-time connectivity, i.e., timeliness is one of the distinctive features of the product. Besides connectivity, these services involve the collection, use, and distribution of information of one sort or another. Sometimes the databases are massive. But even more fundamentally, these services involve not just information but also knowledge in the form of software to organize data and information" (CARLSSON, 2004, p. 261, grifo nosso).
\end{abstract}

Nos termos colocados por Carlsson, estes novos serviços envolveriam o "conhecimento na forma de softwares para organizar dados e informação" e a definição de plataformas digitais é quase uma releitura desta afirmação: "Today's digital platforms consist of software processing data in the cloud" (ZYSMAN; KENNEY, 2018, p. 56); organizar este mercado de dados e informação foi precisamente como surgiram as primeiras plataformas digitais, especialmente o modelo do Google (SRNICEK, 2017). Organizar um mercado, coordenar agentes interessados em transacionar neste mercado, realizar a curadoria dos inputs neste mercado, em suma, as plataformas assumiram a tarefa do desenho de mercado (ROTH, 2015). A arquitetura das plataformas, embora admita variações, tem como fundamento orquestrar as interações entre agentes econômicos distintos, para que eles possam gerar e intercambiar valor. Este modelo organizacional, portanto, não se encaixa nas categorias tradicionais de empresas. Parker et al. (2016) citam três tradicionais categorias (produtores de ativos, provedores de serviços, criadores de tecnologias) e a recém-chegada: orquestradores de redes ${ }^{9}$ (PARKER et al., 2016, p. 32). Baseadas em amplo poder computacional, estas "orquestradoras de redes" puderam estruturar estes mercados como outros intermediários analógicos ou manuais não poderiam (PARKER et al., 2016). Quando este modelo organizacional desenhado para o "mercado da informação" realizado pela Google se consolidou, o passo natural era extendê-lo para outros mercados - com a condição de que estes fossem previamente digitalizados, no movimento conhecido como O2O (online to offline) (BRYNJOLFSSON e McAFFE, 2017, p. 143-144). Daí a co-evolução entre os processos de digitalização e plataformização.

Resulta desta breve reflexão uma hipótese a ser testada futuramente: o espaço econômico virtual, de redes horizontalizadas, não-estruturadas, característico da 'nova economia', funcionou como ambiente de seleção das possíveis novas trajetórias organizacionais, culminando com a emergência e difusão das plataformas digitais.

Há evidências iniciais de que esta capacidade estruturante das plataformas é seu traço distintivo e sua vantagem comparativa sobre outros modelos organizacionais dado o contexto de seleção. Pequenas e médias empresas que desenvolvem competências em plataformas digitais conseguem "melhor adquirir e organizar informação estruturada de parceiros externos" (CENAMOR et al., 2019, p. 198, tradução livre) e a competência de redes baseada em plataformas permite "receber conhecimento heterogêneo de diversas fontes em uma forma estruturada" (CENAMOR et al., 2019, p. 198, tradução livre). O ambiente econômico será cada vez mais marcado pela explosão de dados derivada da internet das coisas (IoT) e internet industrial das coisas (IIoT), processo marcado pela fragmentação de aparelhos conectados gerando informações de fontes heterogêneas, um ambiente que "precisa de plataformas que possam mitigar esta complexidade" (DE REUVER et al., 2019, p. 129). Castells se aproxima desta interpretação evolucionária (CASTELLS, 2017, p. 219). Ao levantar a questão de porque "a empresa em rede é a forma

\footnotetext{
${ }^{9}$ Ou seja, ao enfatizar a importância das redes, Castells estava correto. A empresa em rede configura-se como uma elaboração genérica, enquanto a plataforma apresenta-se como a forma histórica específica que a organização tomou para aproveitar o potencial das redes. Sua extrapolação para um mundo no qual "a unidade operacional real torna-se o projeto empresarial possibilitado por uma rede, em vez de empresas individuais ou agrupamentos formais de empresas" (CASTELLS, 2017, p. 229), no entanto, se deve (i) ao momento de sua análise, em que a disrupção ainda se dava entre pipelines eficientes versus pipelines não eficientes e (ii) a não inclusão dos direitos de propriedade em sua análise, como um limitante da projetada perda em importância da empresa individual.
} 
organizacional da economia informacional", ele afirma que as organizações bem-sucedidas (ou seja, selecionadas) são as que geram (i) conhecimento e processam informações eficientemente, (ii) se adaptam à geometria cambiante da economia global, (iii) são flexíveis para transformar seus meios e objetivos e (iv) tem na inovação sua principal arma competitiva. "Essas são, na verdade, as características do novo sistema econômico [...] Nesse sentido, a empresa em rede concretiza a cultura da economia informacional/global" (CASTELLS, 2017, p. 238).

À sua maneira, ele percebe a emergência e o aperfeiçoamento do novo modelo organizacional como um processo evolutivo, embora tome um processo que acabou sendo uma reintermediação (PARKER et al., 2016; EVANS; SCHMALENSEE, 2016) por um processo em que a empresa se transformaria em "uma teia de redes múltiplas" (CASTELLS, 2017, p. 257). No fim das contas, em seu aspecto organizacional, a proclamada revolução digital poderia ser chamada de evolução digital. É claro que os traços que observamos na economia digital são um prolongamento do que começou a ser desenvolvido na 'nova economia'. Não há um momento claro de ruptura, embora existam autores que propõe uma cronologia (BRYNJOLFSSON; McAFFE, 2017, p. 18). A divisão é clara apenas no universo dos conceitos utilizados para descrever determinado período do capitalismo, já que alguns elementos amadureceram. De qualquer forma, o estabelecimento das plataformas como best-practice organizacional marcaria a consolidação da 'economia digital', conforme resumido no quadro 1. Um dos pontos na agenda de pesquisa do campo de plataformas digitais se dedica a investigar a gênese das plataformas digitais (DE REUVER et al., 2019) e os pontos apresentados aqui são apenas introdutórios. Dito isto, nos voltamos em seguida para as características mais relevantes das plataformas digitais.

\section{Quadro 1 - Características da Nova Economia e da Economia Digital}

\begin{tabular}{|c|c|c|}
\hline & Nova Economia & Economia Digital \\
\hline Principais Tecnologias & $\begin{array}{l}\text { Internet banda larga, tecnologia } \\
\text { mobile, } 2 \mathrm{G}, 3 \mathrm{G}\end{array}$ & $\begin{array}{l}\text { Internet das Coisas, Blockchain, } \\
\text { Computação na Nuvem, } \\
\text { Manufatura Aditiva, 4G, 5G }\end{array}$ \\
\hline Modelo Organizacional & $\begin{array}{c}\text { "Empresa em rede"; pipelines } \\
\text { eficientes }\end{array}$ & Plataformas \\
\hline Indústrias Transformadas & Mídia, Varejo, Logística & $\begin{array}{l}\text { Agricultura, Comunicação, Bens } \\
\text { de Consumo, Educação, Energia } \\
\text { e Ind. Pesada, Trabalho e } \\
\text { Serviços } \\
\begin{array}{l}\text { Logística, OS, Profissionais, } \\
\text { Turismo }\end{array}\end{array}$ \\
\hline Vantagem Comparativa & $\begin{array}{l}\text { Eficiência, otimização } \\
\text { distributiva, ampliação de } \\
\text { mercados }(e \text {-commerce })\end{array}$ & $\begin{array}{l}\text { Efeitos de rede, ecossistemas de } \\
\text { inovação, ganho de escala sem } \\
\text { ativos, estratégia de dados }\end{array}$ \\
\hline $\begin{array}{l}\text { Época (Brynjolfsson e } \\
\text { McAffe, } 2017: 18)\end{array}$ & $1995-2010$ & $2010-$ \\
\hline Paradigma de Inovação & $\begin{array}{c}\text { Inovação Aberta (Chesbrough, } \\
\text { 2003) }\end{array}$ & $\begin{array}{c}\text { Inovação recombinante } \\
\text { (Brynjolfsson e McAffe, 2014); } \\
\text { convergente e generativa (Yoo } \\
\text { et al, 2012); data driven } \\
\text { innovation (DDI) }\end{array}$ \\
\hline
\end{tabular}

Fonte: elaboração própria a partir de diversos autores

\section{Plataformas Digitais}

Plataformas não são uma invenção do século XXI. Na verdade, as feiras na idade média têm bastante em comum com algumas das plataformas mais modernas cujo foco é reorganizar e fomentar 
mercados (EVANS; SCHMALENSEE, 2016; FISMAN; SULLIVAN, 2016). Quando este mercado não se estabelece espontaneamente e exige um certo grau de coordenação e gerenciamento por parte do market maker - seja a feira medieval de Champagne ou a plataforma digital de hotelaria on-demand AirBnb - este mercado qualifica-se como uma plataforma (FISMAN; SULLIVAN, 2016). Não obstante, $\mathrm{o}$ advento das plataformas digitais incrementou a fronteira de possibilidades das plataformas, bem como seu alcance. Gawer (2014, p. 1245) define plataformas como "organizações ou meta-organizações em evolução" que cumprem três requisitos fundamentais: (i) elas agregam e coordenam agentes que podem inovar e competir, (ii) criam valor ao gerar e cultivar economias de escopo de oferta e/ou de demanda e (iii) apresentam uma arquitetura tecnológica modular e composta de centro e periferia.

Com esta definição, a autora procura conciliar duas correntes de pesquisa dedicadas às plataformas: design industrial e teoria econômica. Sua definição é enriquecedora para os dois campos, pois imputa a questão da agência, até então ausente nas definições provenientes do design industrial e exige dos economistas o reconhecimento da base tecnológica tão bem devassada pelos estudos de sistemas de informação e infraestrutura (GAWER, 2014, p. 1245). Gawer se interessa por plataformas que promovam algo mais além da troca de informações, bens ou serviços e algum tipo de moeda (PARKER et al., 2016, p. 36): a dinâmica da inovação a partir da interação da plataforma com o ecossistema que a circunda. Por este motivo, definições tais quais: "A platform is a business based on enabling value-creating interactions between external producers and consumers" (PARKER et al., 2016, p. 5) não estão equivocadas, estão apenas incompletas (neste caso, uma versão simplificada dos pontos 1 e 2 de Gawer apresentados acima).

Gawer (2014) enfatiza, desde sua definição, a importância de entender a inovação no contexto deste novo modelo organizacional. Dois pontos são relevantes: (i) a literatura que trata da problemática da precificação para as plataformas é um caso especial dentro do universo das plataformas (GAWER, 2014, p. 1245) - que a autora opta por chamar de plataformas transacionais. Podemos pensar no modelo Uber como um destes casos, dado que a participação de passageiros ou de motoristas é mediada quase que exclusivamente via preços, e sua colaboração para a inovação dentro da plataforma é mínima. No Brasil, iFood, Gympass, Arco Educação, 99, Nubank e Stone Pagamentos são todas plataformas transacionais - e ainda tem em comum o fato de possuírem avaliação de mercado acima de 1 US\$ bilhão (NAOE, 2019). Diferentemente, plataformas inovativas são aquelas que propiciam uma arena na qual agentes externos competem e colaboram, inovando e disputando os frutos desta atividade geradora de valor ${ }^{10}$. Esta comunidade composta pela plataforma e seus colaboradores/complementadores é o ecossistema de inovação (EVANS; GAWER, 2016, p. 6). Google e Facebook são alguns dos clássicos exemplos de plataformas inovativas; no Brasil, podemos mencionar a Dojot, mantida pelo CPqD e dedicada a soluções de Internet das Coisas. A arquitetura destas organizações permite à complementadores "produzir conteúdo para a plataforma para expandir suas funcionalidades" (PARKER et al., 2016, p. 7, tradução livre) apropriando-se de parte do valor gerado. Assim, inovar deixa de ser o terreno "dos especialistas inhouse e dos laboratórios de $\mathrm{P} \& \mathrm{D}$, passando a ser produzida a partir de crowdsourcing e pela contribuição de ideias de participantes independentes na plataforma" (PARKER et al., 2016, p. 12, tradução livre).

A definição de Gawer não se atém apenas a plataformas digitais. Apesar disso, a autora reconhece a distinção das plataformas digitais dentre as demais (GAWER, 2014, p. 1243). Parker et al. (2016, p. 5) entendem as plataformas digitais como um modelo superior - um upgrade organizacional permitido pela digitalização. Kenney e Zysman (2016) chegam a defender a existência de uma digital platform economy (KENNEY; ZYSMAN, 2016, p. 62). Repetindo a definição destes mesmos autores trazida na introdução, plataformas digitais são "frameworks digitais multilaterais que intermediam e dão forma às regras que os participantes obedecem ao interagir entre si" (KENNEY; ZYSMAN, 2018, p. 56, tradução livre). Cumpre notar o surgimento do termo "participantes": a plataforma digital é composta por (i) plataforma (controlador da plataforma) e (ii) ecossistema, que podem ser apenas usuários das plataformas ou complementadores, agentes econômicos independentes que vão inovar modificando e incrementando os

\footnotetext{
${ }^{10}$ Evans e Gawer (2016) também definem plataformas de investimento e plataformas integradas. As últimas são ao mesmo tempo plataformas transacionais e inovativas.
} 
elementos básicos fornecidos pela plataforma. Teece (2018, p. 1375) menciona como o progresso e a difusão de tecnologias digitais leva à pervasividade das plataformas digitais. No entanto, o ponto fundamental que enfatiza a relevância das plataformas digitais encontra-se em Yoo et al. (2012): os autores são enfáticos ao correlacionar a emergência de plataformas digitais com a possibilidade de se fomentar inovação baseada em processos acelerados de convergência e generatividade, propriedades atribuídas à inovação na economia digital e correlacionadas à emergência das plataformas digitais.

As tecnologias digitais e a imaterialidade digital levam a duas novas tendências de inovação organizacional: convergência e generatividade. A convergência ocorre (i) a partir da consolidação em um mesmo lugar de várias experiências de usuário previamente separadas (ao se combinarem os canais de acesso, aquisição e consumo de produtos e serviços digitais como Internet, TV, telefone); (ii) em função da multiplicidade de artefatos smart, conectados à rede; e (iii) em função da convergência de indústrias antes separadas. A generatividade decorre (i) da possível adição de novas funcionalidades a um produto/serviço já lançado (ou seja, seu caráter reprogramável deixa sempre uma porta aberta para complementação); (ii) decorre também da natureza expansiva do digital que ocorre com gargalos, sempre que uma nova tecnologia entra em cena ela exige novos modelos de negócio e (iii) a generatividade brota da "pegada digital" que as atividades produzem como subprodutos - a possibilidade de registrar cada comportamento de consumo, reação, etc., na esfera digital permite a exploração destes dados para novos negócios (YOO et al., 2012, p. 1399-1400). Resumindo o exposto até aqui, as plataformas apresentam duas grandes categorias de ganhos econômicos:

- A criação de novos mercados e a reintermediação/reorganização de mercados préexistentes com ganhos de eficiência e alcance;

- A fundação de uma nova dinâmica inovativa, amparada na digitalização e sintetizada pela convergência e generatividade

Como as plataformas digitais procederam para permitir tais avanços? Parker et al. (2016) mencionam alguns pontos nos quais as plataformas superam suas predecessoras, as pipelines. Em primeiro lugar, as plataformas reconfiguram a criação de valor ao usar novas fontes 'produtoras'. Isso significa que ao invés de produzir o produto que carrega valor, a plataforma traz para junto de si outros agentes econômicos que já o fazem ou que receberão incentivos para tanto. Ao invés de produzi a Barsa, com especialistas, a plataforma vai se escorar na multidão de colaboradores da Wikipedia. Esse fato conversa diretamente com a visão de inovação distribuída ${ }^{11}$ (YOO et al., 2012) e, se extrapolada para outro âmbito, como a pesquisa científica, ressoa no conceito de citizen science (OCDE, 2015). O segundo feito das plataformas é reconfigurar mecanismos de consumo. Ao criar laços de confiança que não existiriam de outra maneira via sistemas de rating e outros mecanismos, a plataforma digital incentivou que pessoas se hospedassem na casa de estranhos e pegassem carona no carro de estranhos (PARKER et al., 2016, p. 48). O terceiro feito é a curadoria de conteúdo fundamentada na própria comunidade de usuários: para excluir conteúdo indesejado, além de uma boa estratégia de dados, a plataforma precisa criar mecanismos de participação da sua comunidade, uma forma distribuída de limpar ofertas indesejáveis e usuários mal-intencionados do ecossistema.

Resulta deste modelo organizacional três rupturas no modelo tradicional (PARKER et al., 2016): rompe-se a ligação entre ativos e valor. Não parece algo muito radical se pensarmos que é, basicamente, uma nova forma de "aluguel" fracionado. Claro, o que antes se fazia com contratos agora foi agilizado pelas plataformas, diminuindo a friç̧ão do mercado e incentivando o engajamento de mais usuários. Esta transformação de produtos em serviços responde a uma tendência que ecoa à financeirização: melhor alocação de recursos ociosos, não importa se este recurso é dinheiro, seu veículo ou uma caixa de ferramentas. $O$ foco na alocação para geração de valor também é o que permite que as plataformas cresçam exponencialmente (SRNICEK, 2017). Outro ponto é a reintermediação: ao invés de

\footnotetext{
11 Também conceituada por Tiwana (2014) como "massively distributed innovation". OCDE (2019) ressalta que dentre os quatro principais eixos estruturantes de política de inovação digital, um é dedicado à "promover a inovação colaborativa".
} 
desintermediação o que ocorreu foi a substituição de velhos intermediários ineficientes por plataformas online capazes de articular com mais eficiência e alcance diferentes grupos de usuário graças aos efeitos de rede ${ }^{12}$. Finalmente, a agregação de mercado é o terceiro ponto imposto pelas plataformas sobre suas concorrentes: ao canalizar redes dispersas, a plataforma cria o que Roth (2015) chama de densidade e liquidez à mercados antes rarefeitos.

Estas características da plataforma digital permitem compreender porque ela altera substancialmente os processos de inovação e porque coloca os dados no centro do palco. Yoo et al. (2012) defendem que a plataforma ganha espaço com a emergência do digital, já que ela é o modelo que permite às empresas aproveitarem a convergência e a generatividade já mencionada. Além disso, as plataformas também podem ser internas à empresa - um ponto caro a Gawer $(2009 ; 2014)$ - facilitando a reutilização de competências digitais para tarefas ou funções diferentes (YOO et al., 2012, p. 1400). Há, todavia, um tradeoff que as empresas enfrentam ao mobilizar plataformas digitais para aproveitar os novos traços da inovação digital: elas precisam calibrar o grau de abertura, ou as camadas nas quais elas deixaram penetrar os complementadores independentes. Calibrar o grau de abertura significa incorporar em seu código e na governança da plataforma os limites à arbitrariedade dos complementadores individuais. Muito controle pode manter a maior parcela do valor gerado e mantém os ativos estratégicos da plataforma fora de risco, mas afasta colaboradores; muita abertura atrai colaboradores, mas dispersa valor e pode engendrar efeitos de rede negativos, como uma debandada de usuários buscando plataformas mais estáveis. É neste tradeoff fundamental que Boudreau e Lakhani (2009) encontram um continuum de abertura, ou de autonomia desfrutada pelos agentes envolvidos em cada um dos arquétipos propostos: a mais fechada é a integrator platform business model. No meio termo estão as product platform business model e as mais abertas são multisided platform business model.

Antes de passar ao tópico seguinte, é preciso mencionar os desafios sociais e econômicos que estão atrelados à emergência das plataformas como modelo organizacional. Toda uma literatura vem sendo construída para analisar a subsunção do trabalho humano às plataformas digitais (BEARSON et al., 2019), mas como demonstramos aqui, plataformas de trabalho e serviços profissionais são somente uma fração do universo da economia das plataformas. Não obstante, esta é uma área sensível e especial, que deve receber atenção do poder público no sentido de regulamentação para operar dentro de padrões mínimos. Parker et al. (2016) listam, como temas a serem debatidos a política tributária, a política de dados, o acesso aos ativos nacionais de informação por plataformas estrangeiras, a concorrência justa, a precificação justa e o acesso equânime à bens e serviços disponibilizados pelas plataformas. Todos estes pontos merecem uma sessão específica para serem debatidos, o que não é possível no escopo deste artigo, embora alguns deles reapareçam na análise a seguir.

\section{Política de Inovação Digital: A E-Digital}

O documento intitulado Estratégia Brasileira para a Transformação Digital (MCTIC, 2018) dá a impressão, de início, de apresentar um amplo escopo. Afinal, a anunciada transformação digital, necessária para adequarmos à revolução digital é um fenômeno social amplo e multidimensional. No entanto, desde sua introdução a ênfase recai sobre as transformações estritamente econômicas no bojo da mencionada revolução (a exceção ao tratamento econômico ocorre no item "confiança no ambiente digital", que trata de proteção de direitos pessoais, privacidade e segurança e soberania nacional). O documento relaciona a transformação digital à aumentos na produtividade, geração de emprego e renda e prosperidade social. Após constatar a defasagem nacional com relação a iniciativas no sentido de formar

\footnotetext{
12 "Network externalities imply that a technology's usefulness increases as its installed base of users increases" (DE REUVER et al., 2018, p. 125). Os efeitos de rede podem ser diretos, quando o valor da rede aumenta para um grupo à medida que esse mesmo grupo aumenta; ou indireto, quando o valor da rede aumenta para um grupo quando usuários em outro grupo aderem à rede.
} 
uma economia digital robusta, são expostos os dois eixos com o qual se desenhou a E-Digital: eixos habilitadores e eixos de transformação digital.

Os eixos habilitadores, encarados como pré-requisitos, são cinco (entre parênteses indicamos o número de ações previstas para cada eixo): Infraestrutura e acesso às TICs (9); Pesquisa, Desenvolvimento e Inovação (10); Confiança no Ambiente Digital (15); Educação e Capacitação Profissional (9); Dimensão Internacional (10). Os eixos de transformação digital são quatro: um relacionado ao governo, Cidadania e Governo (11), e três relacionados à economia, Economia Baseada em Dados (6); Um Mundo de Dispositivos Conectados (6) e Novos Modelos de Negócios (24). O documento aporta contribuições importantes e traz destaque positivos. O destaque dado à expansão da infraestrutura de TICs demonstra o entendimento de que a economia digital tem uma sólida base real/tangível que demanda atenção. A indispensável atualização do direito é foco do eixo "confiança no ambiente digital". O eixo habilitador "educação e capacitação profissional" tem o mérito de enfatizar a importância da reformulação da educação básica para um país digitalmente letrado no futuro - no entanto, não toca na questão da capacitação da mão-de-obra corrente para novas oportunidades geradas pela transformação digital; tampouco faz qualquer alusão à mecanismos para evitar a fuga de mão-de-obra capacitada para o exterior e/ou repatriamento daqueles que deixaram o país. Vamos analisar com mais detalhes um eixo habilitador, 'pesquisa, desenvolvimento e inovação' e um eixo de transformação digital: 'novos modelos de negócios'.

Em 'pesquisa, desenvolvimento e inovação' o documento enfatiza dois pontos: (i) protagonismo do país no cenário global no tocante ao desenvolvimento de tecnologias digitais e (ii) resolução de amplos problemas sociais com a aplicação destas tecnologias (MCTIC, 2018, p. 25), em um tom que evoca o clássico chamamento latino-americano em estudos da inovação como vetor para a melhoria dos indicadores sociais. Na parte seguinte, o Diagnóstico, a E-Digital incorre em um problema não exclusivo deste documento: a utilização de indicadores clássicos para analisar a economia digital (ZACKIEWICZ, 2015 , p. 315). A primeira parte da análise dedica-se à comparação dos percentuais de investimento em P\&D entre países, especificamente no "setor de TICs". Zackiewicz (2015), bem como outros autores (BRYNJOLFSSON; MCAFFE, 2014) testemunham que a economia digital há tempos deixou de estar contida num setor específico e que os indicadores tradicionais pouco são capazes de auxiliar na tarefa de mensurar seu impacto na economia ${ }^{13}$. Conclui-se que nem o nível de análise - setorial - tampouco os indicadores mobilizados - volume e percentual de investimento em P\&D - são suficientes para esboçar um diagnóstico preciso de PDI relevante à economia digital. Com respeito à Visão, é mencionada a importância de ações baseadas em métodos de foresighting e forecasting e se dá atenção especial ao desenvolvimento de tecnologias habilitadoras (enabling technologies). Teece (2018) coloca as tecnologias habilitadoras como "quase-GPTs", i.e., um nível abaixo em termos de pervasividade econômica que as tecnologias de propósito geral (general purpose technologies - GPT). A Visão é concluída com uma lista de objetivos bastante genéricos: aumento do investimento em PDI no setor; melhoria da perspectiva orçamentária; utilização de public procurement; adensamento do sistema nacional de inovação; roadmap para ciberinfraestrutura; capacitação de mão-de-obra e segurança contratual/jurídica. Por fim, há um número de Ações Estratégicas propostas, focadas em apostas setoriais (em oposição as tecnologias habilitadoras presentes na Visão): Segurança e Defesa, Saúde, Agronegócio, Cidades Inteligentes complementadas por ações - já mencionadas anteriormente - de compras públicas para estimular o desenvolvimento de tecnologias digitais, realização de cenários prospectivos. O único ponto que conversa especificamente com a realidade da economia digital é o desenvolvimento de technology hubs e ambientes experimentais (testbeds) (MCTIC, 2018). Muito pouco para um eixo habilitador tão importante dentro da E-Digital. Além disso, chama atenção a quase completa ausência de qualquer ligação entre demandas sociais, tais como saneamento básico, habitação, transporte público (a exceção sendo o setor de Saúde) e a Visão/Ações propostas, em claro desacordo com o que havia sido declarado no início do documento.

\footnotetext{
13 Por esta razão algumas instituições vem trabalhando no desenvolvimento de indicadores para a economia digital, e.g., FMI, (2018); citando o aspecto da servitização da economia digital, OCDE (2018, p. 35) afirma que "service innovation is often not based on R\&D at all”, explicitando a necessidade de se avançar no desenvolvimento de novos indicadores.
} 
O eixo 'novos modelos de negócio' começa com uma definição equivocada do que são plataformas digitais: "[...] este termo [plataformas digitais] faz referência a serviços e funcionalidades disponibilizados pela Internet tão variados quanto mecanismos de busca, mídia social, plataformas de comércio eletrônico, lojas de aplicativos online, sites de comparação de preço, entre outros" (MCTIC, 2018, p. 75). Como exposto na sessão anterior, plataformas digitais tem definições bastante diferentes da proposta, que reduz a plataforma digital ao comércio eletrônico (e-commerce $)^{14}$. Por tabela, a importância da plataforma é reduzida à inserção marginal das empresas brasileiras como usuárias de plataformas, como integrantes do ecossistema de plataformas globais estabelecidas. É uma clara alusão aos benefícios de primeira ordem de que fala Arbache (2018). Mais do que isso, é uma visão puramente comercial do fenômeno das plataformas digitais e da economia digital. A E-Digital segue uma tipologia de plataformas proposta pela EU: mercados online, ecossistemas móveis e plataformas de distribuição de aplicativos, serviços de busca na internet, plataformas de mídia social e de conteúdo, plataformas de anúncios publicitários online. Esta tipologia que se assemelha a de Srnicek (2017) opta por categorizar plataformas de acordo com o serviço oferecido; tem a vantagem de oferecer uma visão com maior granularidade para cada categoria, porém deixa passar as grandes características em comum que as unem e que permitem a elaboração de políticas públicas para agregados maiores. Na Visão, os três primeiros pontos são inquestionáveis: reconhecimento das plataformas como novos agentes de inovação, regulação do uso pessoal de dados e do poder de monopólio que as plataformas podem exercer; o quarto ponto, "Estímulo ao desenvolvimento de empresas nacionais atuantes nos mercados de plataformas digitais, buscando ampliar a segurança jurídica e a apropriação dos ganhos de exploração desses mercados" (MCTIC, 2018, p. 80) perde a oportunidade de mirar no desenvolvimento de plataformas digitais nacionais, com tecnologia nacional, formando ecossistemas de inovação nacionais como primeiro estágio de um processo de internacionalização. As Ações Estratégicas são bem colocadas: atualizar o marco normativo com vistas à inovação, exigência de algoritmos que respeitem direitos fundamentais, transparência nos critérios adotados em seus algoritmos e aprimoramento da competição entre plataformas digitais. Em seguida, outros 'modelos de negócio' são analisados, como plataformas de comércio eletrônico (embora seja difícil distinguir entre estas e aquelas denominadas marketplaces na definição apresentada), plataformas de economia criativa (música) e uma análise do 'empreendedorismo digital', que acaba focando-se nos desafios para fomentar uma cultura de startups e outras pequenas empresas de base tecnológica.

\section{Discussão}

A E-Digital é uma iniciativa pioneira muito bem-vinda que posiciona o Brasil junto a outros países que já elaboraram suas próprias estratégias digitais (CEPAL, 2016). Nesta sessão pretendemos discutir alguns pontos específicos do documento. A E-Digital, muito pela maneira como foi construída, com ampla participação da academia, empresas, governo, tece um panorama bastante amplo sobre a transformação digital. É meritório a aproximação com os ODS e sua visão de longo prazo. Ela também tangencia a maioria dos temas relevantes internacionalmente - como a já conhecida lista de tecnologias habilitadoras da "revolução 4.0" que será a base da Internet industrial e que é acompanhada pelo crescimento de plataformas industriais como a GE e a Siemens (SRNICEK, 2017). O documento discorre sobre uma grande quantidade de ferramentas e instrumentos públicos que, mobilizados, permitiriam alcançar a visão almejada para cada eixo proposto. Alguns pontos, no entanto, merecem consideração mais aprofundada:

\section{Articulação com objetivos governamentais mais amplos}

\footnotetext{
14 Esta abordagem reducionista surge em outras partes do documento, especialmente no eixo habilitador 'Dimensão Internacional': “O Brasil é responsável por 39\% do volume de comércio eletrônico B2C em toda a América Latina. A importância desse segmento de mercado de plataformas digitais para o comércio eletrônico tende a crescer com o processo de integração e de adensamento da cadeia de valor na América Latina" (MCTIC, 2018, p. 57) e ainda, "O processo de internacionalização das empresas brasileiras via e-commerce deve se dar em fases, envolvendo numa primeira etapa a criação e gestão de sítio próprio na Internet, seguido de uma segunda fase de internacionalização da plataforma digital” (MCTIC, 2018, p. 58).
} 
Embora faça referência à versão mais recente da Estratégia Nacional de Ciência, Tecnologia e Inovação (MCTIC, 2016), a E-Digital lista uma centena de ações estratégicas que não estão subordinadas ou conectadas à programas específicos, seja do próprio MCTIC ou encabeçados por outros ministérios. A política de atração de centros de dados, por exemplo, é uma ação estratégica mencionada sem um lastro em programa ou estratégia governamental existente ou a ser produzida. Além disso, a multiplicidade de eixos, visões e ações propostas leva a uma sensação de falta de foco ou dispersão dos esforços e dos recursos disponíveis. É preciso, citando Arbix e Miranda (2017, p. 67), de uma "política de conjunto, multi-institucional", mas focada e com objetivos claros. Ou como enfatizado em OCDE (2019, p. 11, tradução livre), "Alinhamento é necessário não somente entre políticas de inovação, mas também entre outros domínios políticos (pesquisa, educação, competição, esfera tributária, etc.).

\section{Indefinição de Agência}

Retomando o início da E-Digital, o documento afirma que ao "Aproveitar todo o potencial das tecnologias digitais" (MCTIC, 2018, p. 6), o resultado, no longo prazo, será produtividade, competitividade, níveis de renda e emprego melhores. No entanto, ao final do documento ainda há dúvidas sobre quem são os agentes aderentes à estratégia proposta, ou quem irá investir em cada ação proposta. Há eixos, como 'cidadania digital e governo', que dizem respeito claramente ao papel do Estado. No entanto, ao mesmo tempo em que se reconhece a timidez do setor privado no necessário investimento em PDI para alavancar diversos pontos discutidos no documento, não se constroem alternativas a este cenário. Em outros termos, a E-Digital parece se apoiar numa espécie de política tecnológica "orientada para a difusão" (ERGAS, 1987), que espera que o setor privado, associações industriais e/ou cooperativas de pesquisa tomem naturalmente a liderança do processo de transformação digital. Este tipo de PCTI tem como marca distintiva a descentralização (ERGAS, 1987, p. 66), um traço que parece se adequar à visão que emana da E-Digital. Embora esta seja uma escolha legítima dos formuladores da política pública, cabe questionar a viabilidade desta alternativa. A alternativa analisada por Ergas (1987) é a política tecnológica “orientada por missões”, cuja principal característica seria a centralização. Este tipo de estratégia é comumente aplicado por países que buscam excelência e liderança global em uma área ou setor específico (ERGAS, 1987, p. 53), exatamente o que a própria E-Digital propõe: "As iniciativas brasileiras para PD\&I devem almejar o protagonismo do País no cenário mundial em tecnologias digitais, com avanço nas posições relativas em produção científica, desenvolvimento tecnológico e inovação, nomeadamente nos setores de tecnologia da informação e comunicação" (MCTIC, 2018, p. 25),

\section{Paradigmas de Inovação}

A visão de inovação que prevalece no documento mistura elementos do paradigma da inovação aberta (CHESBROUGH, 2003), como em "Um ( sic) política efetiva para abertura de dados é crucial para a construção de espaços experimentais, nos quais cidadãos inovadores e participativos possam interagir de perto com os agentes públicos na busca da solução de problemas da sociedade [...]" (MCTIC, 2018, p. 97) e elementos do 'paradigma nascente' de data driven innovation (OCDE, 2015), como em "O acesso a tais insumos pauta a própria inovação baseada em dados, caracterizada pela utilização de dados e analytics para melhorar ou promover novos produtos, processos, métodos organizacionais e mercados" (MCTIC, 2018, p. 61).

Não entendemos estas duas abordagens como incompatíveis. O que poderia ter sido incorporado ao documento é a conjugação deste processo acelerado de criação e disponibilização de dados com a inovação organizacional que corresponde às plataformas digitais. $\mathrm{O}$ uso dos dados como insumo para inovar e aperfeiçoar produtos e serviços ocorre nas plataformas de maneira ótima - afinal, como novas intermediárias de amplos mercados (e até mesmo de algumas funções sociais, e.g., encontrar um veículo leve para mobilidade urbana), seu posicionamento as possibilita recolher e tratar uma expressiva quantidade de dados gerados no transcorrer dos processos produtivo, distributivo, de consumo e pósconsumo, etc. A grande complementaridade das plataformas e da digitalização indicam para um processo de co-evolução, embora isto ainda deva ser objeto específico de investigação. 
Compreender a plataforma como o modelo organizacional de excelência no contexto da inovação digital poderia também ter levado os formuladores do documento a incluir as modificações que estão ocorrendo na seara da investigação científica (OCDE, 2015, cap.7; FABRE, 2016) bem como o desenvolvimento de plataformas públicas (HAUTAMAKI; OKSANEN, 2018; YU et al., 2019; BROWN et al., 2016). Um modelo organizacional torna-se uma best-practice ao transbordar das empresas para organizações de pesquisa, governamentais, etc. O não entendimento do modelo organizacional implica também um entendimento parcial dos processos de inovação viabilizados por ele. A dinâmica convergente e generativa da inovação digital (Yoo et al., 2012) está intrinsecamente conectada a agência das plataformas digitais.

\section{Plataformas Digitais}

De início, o documento poderia ter se debruçado com mais atenção sobre o modelo organizacional que sustenta a revolução digital: as plataformas digitais. A mobilização de definições e conceitos imprecisos torna a visão e as ações estratégicas propostas pouco congruentes. A E-Digital não se aprofunda no entendimento das plataformas digitais como lugar central dos ecossistemas de inovação como um agente privilegiado de inovação, portanto. Tampouco o documento se dedica a repensar modelos de propriedade intelectual mais adequados a nova forma de co-criação, padrão dentro de arranjos ecossistêmicos.

Isto se dá porque, como apresentamos, o documento privilegia as plataformas transacionais, entendidas como marketplaces ou 'plataformas de comércio exterior'. No entanto, mesmo quando se refere à essa categoria, a E-Digital promove uma estratégia subordinada de inserção das empresas brasileiras na economia digital: como usuárias de plataformas já estabelecidas. Não resta dúvidas de que há muitos ganhos possíveis que derivam desta inserção: eles são o que Arbache (2018) chama de 'ganhos de primeira ordem'; no entanto, as donas ou controladoras das plataformas obtém ganhos de segunda ordem; por coordenarem a plataforma, se apropriam de uma boa parte do valor gerado nela - isto sem mencionar ganhos dinâmicos derivados do acesso ao pool de dados gerados pelo ecossistema circundante. Além disso, tem a possibilidade de estabelecer a governança da plataforma - um ponto que será cada vez mais importante à medida que mais funções sociais (como mobilidade urbana, acesso à saúde, etc.) sejam mediadas por plataformas (ZYSMAN; KENNEY, 2018).

De forma específica, colocaríamos os seguintes pontos como complementos naturais à análise realizada pela E-Digital:

- Criar mecanismos de fomento a plataformas digitais transacionais quando sua ação se sobrepuser a objetivos sociais (e.g., relacionados aos ODS): o reaproveitamento de resíduos é objeto de duas plataformas transacionais complementares, a Cataki, que desfragmenta o mercado de catadores (C2B) e a Pólen, que reintermediou a alocação de resíduos entre empresas (B2B).

- Estimular por meio de concursos, prêmios, editais, a formação de plataformas inovativas nacionais, $100 \%$ privadas ou em parcerias como a Dojot (CPqD).

- Criar plataformas públicas. Assim como empresas públicas são fundamentais para o bom funcionamento da economia e da sociedade, as plataformas públicas serão fundamentais na Economia Digital. A rationale (FAGERBERG, 2017; OCDE 2019) para formação de plataformas públicas não está consolidada. No entanto, é possível divisar desde já algumas especificidades que justificarão o investimento em plataformas públicas: (i) indústrias com alto risco de mismatch (realizar um match equivocado), como a saúde; (ii) indústrias baseadas em informações sensíveis, como saúde e defesa; (iii) plataforma pública como vetor de competição para evitar monopólios em serviços essenciais, como na área de mobilidade urbana (em São José dos Campos, p.ex., a Yellow, plataforma privada que transforma a utilização de bicicletas em um serviço on-demand, coexiste com a plataforma Samba, administrada pelo poder público municipal por meio de sua Secretaria de Mobilidade Urbana - em parceria com a Serttel); (iv) plataformas capazes de fomentar a inovação colaborativa (OCDE, 2019, p.33), que coloquem em contato pesquisadores, universidades, empresas e instituições de pesquisa. 
- Criar um GT específico para identificar áreas da administração pública que possam ser otimizadas via plataformização (HAUTAMAKI; OKSANEN, 2018; BROWN et al., 2016).

- Criar um GT específico para desenvolver novos indicadores para a Economia Digital e para a plataformização. É impossível desenhar políticas baseadas em evidências (evidence-based innovation policies) sem um robusto programa de indicadores e estatísticas padronizadas (FMI,2018) para determinar as linhas de ação, bem como para avaliar os resultados posteriormente.

- De forma democrática a participativa, definir exigências mínimas para plataformas dedicadas a trabalho e a serviços profissionais, como Uber e outras plataformas de entrega ou de microsserviços (BEARSON et al., 2019).

- Refletir sobre o grau de vulnerabilidade e sensibilidade a que a economia de plataforma nacional está exposta $^{15}$, sendo construída sobre plataformas estrangeiras, como os sistemas operacionais Android e iOS e sobre plataformas industriais que virão a fundamentar a indústria 4.0.

Em sua análise, Castells adverte: "Em geral, as redes são assimétricas mas cada um de seus elementos não consegue sobreviver sozinho ou impor suas regras. A lógica da rede é mais poderosa do que seus poderosos" (CASTELLS, 2017, p. 256). A plataforma desafia este veredicto, ao se impor como a artífice de regras que determinam o comportamento de milhões de agentes econômicos; é uma espécie de resposta do capital à ameaça que representava o espaço virtual descentralizado e horizontalizado. Ela endogeniza as redes, criando silos ou currais (SRNICEK, 2017), desta forma elevando a assimetria na rede ao extremo: mantendo o controle sobre o core e permitindo - de acordo com suas regras incorporadas no código do software/algoritmos - variabilidade (ou generatividade) na periferia da sua rede.

Tendo este modelo organizacional contornado a incerteza associada ao aproveitamento econômico das redes e dada uma funcionalidade central aos dados, a própria dinâmica da inovação é alterada e impõe importantes desafios de regulação e política públicas. A política científica, tecnológica e de inovação (PCTI) precisa atualizar-se. Logo no início da E-Digital, o documento versa: "A depender do dinamismo econômico e das principais forças produtivas, alguns países procuram ser líderes em setores específicos e promissores, como a robótica, a inteligência artificial, a manufatura de alta precisão ou as inovações financeiras digitais, enquanto outros gerenciam seus marcos regulatórios de forma a aproveitar o potencial das tecnologias digitais" (MCTIC, 2018, p. 6) Para ir além da passividade implícita na segunda forma de inserção na economia digital, é preciso aprofundar o debate sobre as ações de estímulo à economia digital no Brasil.

\section{Agradecimentos}

À Coordenação de Aperfeiçoamento de Pessoal de Nível Superior pelo suporte financeiro na tese desenvolvida no PPG-PCT, do Departamento de Política Científica e Tecnológica - UNICAMP.

\section{Referências Bibliográficas}

Arbache, J. 2018. Benefícios e Desafios da Economia Digital Para o Desenvolvimento Econômico. In Pesquisa sobre o uso das tecnologias da informação e comunicação nas empresas brasileiras: TIC Empresas 2017. CGI.BR - Comitê Gestor da Internet no Brasil.

Arbix, G., Miranda, Z. 2017. Políticas de Inovação em Nova Chave. Estudos Avançados, 31 (90): 49-73.

\footnotetext{
${ }^{15} \mathrm{O}$ recente episódio em que a Google bloqueou o acesso da Huawei à futuras atualizações em seu sistema operacional demonstra o grau de sensibilidade que a gigante chinesa estava exposta. Em poucos dias a resposta: "A Huawei recebeu, da autoridade chinesa, na semana passada o direito à marca registrada, "Hongmeng", para seu sistema operacional. A empresa tem trabalhado no sistema com o nome de código "Projeto Z", como uma alternativa no caso de perder definitivamente o acesso à tecnologia americana, como o Android, que alimenta os populares smartphones da Huawei” (VALOR, 2019). Resta saber se a empresa obterá sucesso na difícil missão de fornecer um SO alternativo capaz de dirimir não só a sua vulnerabilidade, mas a de outras empresas chinesas - diminuindo a vantagem das plataformas norte-americanas de forma sistêmica sobre a China e sobre o resto do mundo.
} 
Baldwin, C.Y., Woodard, J.J., 2009. The architecture of platforms: a unified view. In: Gawer, A. (Ed.), Platforms, Markets and Innovation. Edward Elgar, Cheltenham, UK and Northampton, Mass, pp. 19-44 Bearson, D., Kenney, M, Zysman, J. 2019. New Work and Value Creation in the Platform Economy: A Taxonomy and Preliminary Evidence. BRIE Working Paper.

Benkler, Y. 2006. The Wealth of Networks: how social production transforms markets and freedom. Yale University Press: New Haven/London.

Boudreau, K. J. 2010. Open platform strategies and innovation: Granting access versus devolving control. Management Science, 56, (10):1849-1872. doi:10.1287/mnsc.1100.1215.

Boudreau, K.J. 2012. Let a Thousand Flowers Bloom? An Early Look at Large Numbers of Software App Developers and Patterns of Innovation, Organization Science 23(5): 1409-1427.

Boudreau, K., K. Lakhani. 2009. How to manage outside innovation: Competitive markets or collaborative communities? Sloan Management Rev. 50(4) 69-76.

Brown, A., et al. 2016. Implementing a Mature Platform. In Brown et al, Digitizing Government: understanding and implementing new digital business models. Palgrave McMillan: Hampshire, UK.

Brynjolfsson, E., McAfee, A. 2014. The Second Machine Age: Work, Progress, and Prosperity in a Time of Brilliant Technologies. New York: W. W. Norton \& Company.

Brynjolfsson, E., McAfee, A. 2017. Machine, Platform, Crowd: Harnessing Our Digital Future. New York: W. W. Norton \& Company.

Carlson, B. 2004. The Digital Economy: what is new and what is not? Structural Change and Economic Dynamics, 15:245-264.

Cenamor, J., V. Parida, J., Wincent. 2019. How entrepreneurial SMEs compete through digital platforms: The roles of digital platform capability, network capability and ambidexterity. Journal of Business Research, 100:196-205.

CEPAL. 2016. Science, Technology and Innovation in the Digital Economy: the state of the art in Latin America and the Caribbean.

Chesbrough, H.W. 2003. Open Innovation: The New Imperative for Creating and Profiting from Technology, Boston, MA: Harvard Business School Press.

De Reuver, M., Sorensen, C., Basole, R. 2018. The Digital Platform: a research agenda. Journal of Information Technology, 33, p. $124-135$.

De Marco et al. 2019. Digital platform innovation in European SMEs: an analysis of SME instrument business proposals and case studies. JRC Technical Reports, European Comission.

Ergas, H. 1987. Does Technology Policy Matter? in Guile B. R e Brooks H. Technology and Global Industry - Companies and Nations in the World Economy, National Academy Press, Washington, D.C.

Evans, P., Gawer, A. 2016. The Rise of the Platform Enterprise: a global survey. The Center for Global Enterprise. The Emerging Platform Economy Series.

Evans, D., Schmalensee, R. 2016. Matchmakers: the new economics of multisided platforms. Boston, Massachusetts: Harvard Business Review Press.

Fabre, R. 2016. New Challenges for Knowledge: digital dynamics to access and sharing. London, UK: Iste, Hoboken, USA: Wiley.

Fagerberg, J. 2017. Innovation Policies: rationales, lessons and challenges. Journal of Economic Surveys, $31(2): 497-512$.

Fisman, R., Sullivan, T. 2016. Everything we know about platforms we learned from medieval France. Harvard Business Review. Disponível em < https://hbr.org/2016/03/everything-we-know-about-platformswe-learned-from-medieval-france $>$.

FMI. 2018. Measuring the Digital Economy. International Monetary Fund Policy Papers.

Gawer, A., (ed.). 2009. Platforms, Markets and Innovation. Cheltenhan, UK: Edward Elgar.

Gawer, A. 2014. Bridging Differing Perspectives on Technological Platforms: Toward an Integrative Framework, Research Policy 43(7): 1239-1249.

Gawer A., Cusumano, M. 2002. Platform Leadership: How Intel, Microsoft, and Cisco Drive Industry Innovation. Harvard Business School Press, Boston, MA.

Goldfarb, A., Tucker, C. 2017. Digital Economics. NBER Working Paper Series. 
Hautamaki, A., Oksanen, K. 2018. Digital Platforms for Restructuring the Public Sector. In Smedlund, A., Lindblom, A., Miltronen, L., (eds.), Collaborative Value Co-creation in the Platform Economy. Springer.

Kenney, M. and J. Zysman. 2016. The rise of the platform economy. Issues in Science and Technology, 32 (3): 61-69.

Kenney, M., P., Rouvinen, T., Seppälä, J., Zysman. 2019. Platforms and industrial change, Industry and Innovation. DOI: 10.1080/13662716.2019.1602514

Lazonick, W., Mazzucato, M. 2013. The risk-reward nexus in the innovation-inequality relationship: who takes the risks? Who gets the rewards?, Industrial and Corporate Change, 22(4), pp. 1093-1128

Mazzucato, M. 2014. O Estado Empreendedor. Desmascarando o mito do setor público vs. setor privado. Ed. Portfolio Penguin, São Paulo.Mazzucato, M. 2017. Innovation, the State and Patient Capital, in Mazzucato, M., e Jacobs, M. (eds.), Rethinking Capitalism: Economics and Policy for Sustainable and Inclusive Growth. Wiley-Blackwell.

MCTIC. 2016. Estratégia Nacional de Ciência, Tecnologia e Inovação 2016 - 2022.

MCTIC. 2018. Estratégia Brasileira para a Transformação Digital (E-Digital).

Moore, M. 2016. Tech Giants and Civic Power. The Centre for the Study of Media, Communication and Power. London: Policy Institute King's College.

Naoe, A. 2019. Empreendedorismo na Universidade. Jornal da USP. Disponível em < https://jornal.usp.br/universidade/usp-formou-10-dos-16-fundadores-de-unicornios-do-brasil// > .

OCDE, 2015. Data Driven Innovation: Big Data for Growth and Well-Being, OCDE Publishing, Paris.

OCDE. 2018. Innovation Policies in the Digital Age. OCDE Science, Technology and Innovation Policy Papers.

OCDE. 2019. The Digital Innovation Policy Landscape in 2019. OCDE Science, Technology and Innovation Policy Papers, nr. 71.

Parker, G., Van Alstyne, M., Choudary, S.P. 2016. Platform Revolution: how networked markets are transforming the economy and how to make them work for you. New York, London: W.W.Norton \& Company.

Perez, C. 1983. 'Structural Change and the Assimilation of New Technologies in the Economic and Social Systems', Futures, Vol. 15, No. 5, pp. 357-75.

Perez, C. 2002. Technological Revolutions and Financial Capital: The Dynamics of Bubbles and Golden Ages. Edward Elgar, Cheltenham.

Roth, A. 2015. Como Funcionam os Mercados. Portfólio Penguin.

Srnicek, N. 2017. Platform Capitalism. Cambridge, UK: Polity Press.

Teece, D. 2018. Profiting from innovation in the digital economy: Enabling technologies, standards, and licensing models in the wireless world. Research Policy, 47, p. 1367-1387.

Tiwana, A. 2014. Platform Ecosystems: Aligning Architecture, Governance, and Strategy. Morgan Kauffman: Walthan, USA.

UNCTAD. 2017. Information Economy Report 2017: Digitalization, Trade and Development.

Valor Econômico. 2019. Huawei desenvolve sistema próprio como alternativa ao Android. Disponível em $<\quad$ https://www.valor.com.br/empresas/6273871/huawei-desenvolve-sistema-proprio-como-alternativa-aoandroid $>$.

Yoo, Y., R. Boland, K., Lyytinem, A., Majchrzak. 2012. Organizing for Innovation in the Digitized World. Organization Science, 23 (5): p. 1398-1408.

Yu, J., et al. 2019. Towards a service-dominant platform for public value co-creation in a smart-city: Evidence from two metropolitan cities in China. Technological Forecasting \& Social Change, 142:168182.

Zackiewicz, M. 2015. A economia do software e a digitalização da economia. Revista Brasileira de Inovação, 14 (2), p. 313-336.

Zysman J. and Kenney, M. 2018. The Next Phase in the Digital Revolution: Intelligent Tools, Platforms, Growth, and Employment. Communications of the Association of Computing Machinery, 61(2): 54-63. 